\title{
Understanding the relationship between depression and diabetic foot ulcers
}

\author{
Andrew Steel ${ }^{1,2}$, John Reece ${ }^{1}$, Anne-Marie Daw ${ }^{3}$ \\ ${ }^{1}$ Department of Psychology, School of Health Sciences, RMIT University, Bundoora, ${ }^{2}$ Department of Orthotics and High Risk Foot Service, \\ and ${ }^{3}$ Psychology, Northern Health, Epping, Victoria, Australia
}

\section{A B S T R A C T}

The prevalence of diabetes is increasing, as is the cost of managing its comorbidities. Diabetic foot ulcers (DFUs) and their complications place a considerable cost burden on the health system, and lead to a significant level of disability. The relationship between depression and diabetes is well-established.The relationship between depression and foot ulcers in diabetic patients is less well-established. The purpose of this article is to provide a current concept review of the literature from I 988 to 2013 , linking DFUs and depressive symptoms, with an emphasis on the impact depressive symptoms have on healing rates of DFUs. Articles specifically focusing on the biological relationship, depression's impact on self-care, screening for depressive symptoms, causes and cost of treating DFUs, and measuring depression were reviewed.A deeper understanding of this relationship is needed to identify causal relationships, improve treatment outcomes, and reduce healing times of DFUs.

Key words: Depression, diabetes, diabetic foot ulcer

\section{INTRODUCTION}

Diabetes is a lifestyle disease of the $21^{\text {st }}$ century. Regardless of the increasing awareness of diabetes, it continues to represent both a national and global health challenge, with estimates that 280 Australians are diagnosed with diabetes every day, and approximately 366 million people were diagnosed with diabetes worldwide in 2011..$^{[1,2]}$ Despite improvements in treatments for patients with diabetes, complications of this disease continue to grow, placing an increased cost burden on the public health system. ${ }^{[2]}$ Diabetic foot complications are the most common reason for diabetic hospital admissions with $12-25 \%$ of patients with diabetes developing a diabetic foot ulcer (DFU). ${ }^{[3,4]}$ Depression is frequently linked to diabetic complications. ${ }^{[5]}$ "Neither the mechanism for the co-occurrence of diabetes

\begin{tabular}{|l|l|}
\hline \multicolumn{2}{|c|}{ Access this article online } \\
\hline Quick Response Code: & Website: \\
\hline & www.joshd.net \\
\hline & \\
\hline
\end{tabular}

and depression nor the directional pattern of causality is known, yet the relationship and its implications are clear" ${ }^{\left[{ }^{[6]}\right.}$ There is strong evidence linking depression as a risk factor for the development of type 2 diabetes and its potential to accelerate diabetes complications, with recent research showing a biological link between depression and diabetes symptoms. ${ }^{[7]}$

The links between depression and exacerbations of health problems, adverse effects on general functioning and quality of life, lower self-care regimens, and poorer glycemic control in people with diabetes are well-established. ${ }^{[8,9]}$ The link between depression and DFUs is less clear, and there is clearly a need to investigate this relationship further. Previous studies have investigated the biological aspects

\footnotetext{
This is an open access article distributed under the terms of the Creative Commons Attribution-NonCommercial-ShareAlike 3.0 License, which allows others to remix, tweak, and build upon the work non-commercially, as long as the author is credited and the new creations are licensed under the identical terms.
}

For reprints contact: reprints@medknow.com

How to cite this article: Steel A, Reece J, Daw AM. Understanding the relationship between depression and diabetic foot ulcers. J Soc Health Diabetes 2016;4:17-24.

Corresponding Author: Mr. Andrew Steel, 145 Park St, South Melbourne, Victoria-3205, Australia. E-mail: info@bodycaresolutions.com.au 
of DFU healing rates such as pressure management, wound factors, and vascularity. These factors and their influence on wound healing are well-understood. A deeper understanding of the influence depressive symptoms may have on healing rates of DFUs is needed to best target appropriate clinical interventions.

The aim of this paper was to comprehensively review recent literature (1988-2013) linking DFUs and depression symptoms, with specific focus on the impact depressive symptoms have upon healing rates. We conclude by discussing the complexities of the relationship between DFUs and depression on individuals and clinical healthcare management, and outline areas where further research is warranted.

\section{DEPRESSION AND DIABETES}

The term depression is used in many different ways: From describing transient states of low mood experienced by all people at some time in their life, through to severe psychiatric disorders. ${ }^{[10]}$ Depression in this article will refer to clinical depression as defined by The Diagnostic and Statistical Manual of Mental Disorders, Fifth Edition (DSM-5). ${ }^{[1]}$ Depression is estimated to become the second most prevalent cause of disease burden and the major cause of disability worldwide by 2020. ${ }^{[12]}$ Over the past 20 years, a number of studies including meta-analyses and systematic reviews have consistently shown that the prevalence of depression in people with diabetes is two to three times more common than the general population. ${ }^{[13-16]}$ The principal conclusion of these reviews was that diabetes doubles the odds of depression, no matter what the subject group, sex, type of diabetes, or assessment method used. ${ }^{[14]}$

The negative impact of depression on individual's quality of life, leading to functional decline, plus the additional burden it has on family members and caregivers, has been well-established. ${ }^{[8,9,17-25]}$ A number of studies have highlighted that depressive symptoms reduced the quality of life in people with diabetes due to somatic symptoms and complications. ${ }^{[6,26,27]}$ These symptoms have been linked with both metabolic and behavioral risk factors for type 2 diabetes. ${ }^{[28]}$ People with depression are less likely to comply with dietary advice ${ }^{[29]}$ and more likely to be physically inactive, ${ }^{[19-23,25]}$ and thus have an increased risk of obesity. This corroborates findings from earlier studies that depressed individuals have higher caloric intake, ${ }^{[21,30]}$ and are less physically active. ${ }^{[19-23,25]}$ A conclusion drawn by the significant longitudinal study into depressive symptoms and incidents of diabetes is that socioeconomic status may act either independently or in combination to influence health-related behavior. ${ }^{[19]}$ An individual with a lower socioeconomic level may be more inclined to consume a diet higher in saturated fats, carbohydrates, and alcohol, as well as maintaining a more sedentary lifestyle leading to a higher predisposition to diabetes. ${ }^{[19]}$

One of the most significant longitudinal studies conducted over 21 years, established that subjects who were found to have the highest levels of depressive symptoms, developed the highest levels of reported diabetes over time, from baseline. ${ }^{[19]}$ The very large sample size and length of study undertaken by Carnethon et al., ${ }^{[1]]}$ carries significant weight, with its conclusions, validity, and reliability into the mediating effect of depression upon diabetes. Subjects who developed higher levels of depressive symptoms over the 21 years were found to be at an elevated rate of 2.52 times more likely to develop diabetes. ${ }^{[19]}$ Further analysis found that those with a low level of education and depressive symptoms were three times more likely to develop diabetes when compared to subjects with higher levels of education. ${ }^{[19]}$ The main limitation of this study was that diabetes levels were only assessed by self-report or from medical records and not a clinical test such as the HbA1c.

Amongst the elderly population, diabetes rarely exists in isolation, ${ }^{[31]}$ with impairment, disability, and higher rates of complications found in patients with both depression and diabetes compared to people with either one of these conditions alone. ${ }^{[31-34]}$ This is further supported by past research indicating a positive relationship between depression and diabetes, with depressive symptoms leading to an exacerbation and acceleration of the onset of diabetes symptoms and complications. ${ }^{[32,35-41]}$ Interesting findings in the research by Golden et al., ${ }^{[7]}$ found that the association between diabetes and depression was not the same for all individuals, and in fact varied with the treatment of diabetes. The suggestion was that requirements in monitoring and treating an individual's diabetes may lead these individuals to elevated depressive symptoms compared to those who did not treat their diabetes. ${ }^{[7]}$ Further research has found the association between type 2 diabetes and incidents of depressive symptoms decreased following adjustments for diabetes comorbidities, ${ }^{[42]}$ thus suggesting that complications of diabetes may be more influential in developing depressive symptoms than diabetes itself.

\section{BIOLOGICAL RELATIONSHIP}

Golden et al., ${ }^{[7]}$ stated that the biological mechanisms by which depression and type 2 diabetes are associated remains 
unclear despite research into the bidirectional association between these two long-term conditions. However, numerous studies allude to linking these two conditions by an inflammatory response at a cellular level, ${ }^{[43,44]}$ which increases the activation of the hypothalamic-pituitaryadrenal axis. Some population studies ${ }^{[45,46]}$ reported that this inflammation is associated with the development of diabetes through limiting insulin uptake, leading to resistance. ${ }^{[35,43,44-49]}$ One suggested association is that obesity or atherosclerosis is associated with low-grade inflammation prior to the onset of diabetes. ${ }^{[16,19]}$

\section{Depression And Diabetes Self-CARE}

Effects of depressive symptoms on a client's ability to selfcare have been explored,${ }^{[50]}$ with symptoms such as reduced energy, appetite, and motivation, plus the cognitive effects associated with depression, impacting individual's ability to self-care. ${ }^{[51]}$ The term 'diabetes burnout' was coined by Barnard et al., ${ }^{[2]}$ to report the feeling of diabetes controlling people's lives, including being overwhelmed and defeated by diabetes and frustrated by the required self-care regime. ${ }^{[2,50]}$

The concept of self-efficacy is important for selfmanagement behaviors for individuals with diabetes. ${ }^{[15,50]}$ Research has found that an individual's ability to comply with treatment directions, instructions, medical adherence, and appropriate preventative care for their diabetes, such as dietary regimes and exercise is diminished when higher levels of depression are present. ${ }^{[52]}$ This concept of diminished self-efficacy impacting on an individual's management of their condition is supported by a controlled trial confirming the hypothesis that people with depression were more likely to engage in behavior known to increase the risk of developing diabetes, and that people who had diabetes complications were more likely to develop depression. ${ }^{[53]}$

There is some limited evidence that interventions to improve depression lead to improvements in general health outcomes; ${ }^{[54]}$ however, other studies have shown that significant improvements in depression levels do not always lead to improved glycemic control. ${ }^{[55]}$ The almost exclusive focus in previous research on the burden of managing diabetes, and the impact on an individual's ability to self-care, has according to Vileikyte et al., ${ }^{[56]}$ neglected to include the chronic complications of diabetes and their effects on an individual's mental health. There is evidence that by improving other comorbidities of diabetes, it is possible to improve depression levels and the ability to self-care, while also reducing the impact of diabetes. ${ }^{[7,22]}$ Complications of diabetes, such as neuropathy and subsequent DFUs, have a significant impact on patients' adherence behaviors, not just their ability to self-care. ${ }^{[56]}$ Research into these adherence behaviors has led to improvements in the methods and education, and information is delivered to patients with an aim to empower individuals in the management of their condition. When patients can be effectively engaged in their treatment, and responsibility for their own care is promoted, health outcomes have been shown to improve. ${ }^{[55]}$

The current focus on physical factors alone has not led to significant reductions in diabetes complications, since a medical model of treatment focuses primarily on adherence to medication. Adopting a more balanced approach and considering the psychological factors associated with diabetes and its complications, may lead to an improvement in treatment outcomes. A longitudinal study investigating the predictors of depression in diabetic patients with peripheral neuropathy (PN) has established that, in patients with diabetes, PN is linked to depressive symptoms and results in activities of daily life (ADL) restrictions and lower self-perceptions. ${ }^{[57,58]}$ This research also established that more severe levels of $\mathrm{PN}$ were associated with strong depressive symptoms, and that these worsened over time. ${ }^{[58]}$ There was also a strong link between an increase in depressive symptoms when combined with a decline in PN-related physical and psychosocial functioning, indicating that, as PN increases its influence on other aspects of life, depression also increases. ${ }^{[58]}$ This is directly relevant to patients with a DFU, as neuropathy is the direct precursor to DFU. The occurrence of a DFU is due to the underlying PN experienced by patients with diabetes.

\section{SCREENING FOR DEPRESSION}

As there is an established link between depression and diabetes, a review of diabetes care guidelines for the screening of depression finds a variety of recommendations. The International Diabetes Federation (IDF) states that healthcare professionals should, in communicating with a person with diabetes, adopt a whole-person approach and respect the person's central role in their ongoing diabetes education and care. ${ }^{[59]}$ There is no specific mention of management of psychological disorders or their impact on diabetes management. Other national and international guidelines are more specific with respect to psychological disorders. By comparison, the British National Institute of Health and Clinical Excellence (NICE) states that: 
"Diabetes professionals should ensure they have appropriate skills in the detection and basic management of non-severe psychological disorders, while arranging prompt referral to specialists of those whom psychological difficulties continue to interfere significantly with their well-being or diabetes self-management."[60]

Once detected, it is recommended that:

"The psychological needs of people with diabetes should be addressed in an organized and planned way and that the individual's psychological status (including cognitive dysfunction) should be assessed periodically, with outcomes and clinical implications discussed with the patient" ${ }^{[60]}$

The American Diabetes Association (ADA) guidelines go slightly further, stating that "assessment of psychological and social situations should be included as an ongoing part of the medical management of diabetes" ${ }^{[61]}$ They specifically state that:

"Psychosocial screening should examine attitudes about the illness, expectations of medical management and outcomes, affect and mood, general and diabetes-related quality of life, resources (financial, social and emotional) and psychiatric history." ${ }^{61]}$

Screening should be provided for psychosocial problems such as depression, diabetes-related distress, anxiety, eating disorders, and cognitive impairment; particularly when self-management is poor. ${ }^{[61]}$

The Australian National Evidence Based Guidelines for the Management of Type 2 Diabetes Mellitus briefly touches on the need for psychosocial management, ${ }^{[62]}$ yet in much less detail than the NICE or the ADA. The National Evidence-Based Guidelines on Prevention, Identification and Management of Foot Complications in Diabetes what was approved by the National Health and Medical Research Council (NHMRC) in 2011 goes into extensive detail on the screening process for 'at risk' subjects for DFUs and the evidence-based management of DFUs. This guideline, however, does not mention or refer to depression or depressive symptoms, and the effect this has on patients with or at risk of DFUs. ${ }^{[63]}$

In some quarters there is a reticence to discuss psychosocial factors with patients, due to the perceived emotional impact that raising such topics may have. A systematic review and meta-analysis on the emotional impact of screening for disease found no evidence of any adverse emotional impact from undergoing a screening process, and reported that their findings are consistent with psychological theories of self-regulation through maintaining emotional equilibrium while managing threats. ${ }^{[64,65]}$ It was concluded that provided standard principals of screening were met, there was no adverse or long-term emotional impact when screening for a disease. ${ }^{[64]}$

\section{DFus-CAuse AND COST}

In Australia in 2005, there were about 10,000 hospital admissions for diabetes-related foot conditions, and over 1,000 people with diabetes died as a direct result of lower limb ulceration, with this representing $8 \%$ of all diabetes-related deaths. ${ }^{[66,67]} \mathrm{PN}$ which affects around $30 \%$ of people with either type 1 or type 2 diabetes, is the major predisposing disorder for diabetic foot disease, ${ }^{[68]}$ with foot deformity, trauma, peripheral arterial disease, and infection being further complicating factors that can prevent or delay ulcer healing. ${ }^{[69-71]}$

The direct cost of treating a DFU and its associated complications is significant when compared to the cost of preventing a DFU. The average cost of preventive care was $\$ A 1,220$ compared with $\$ A 7,260$ for the treatment of an ulcer. ${ }^{[72]}$ When hospitalization was required, the cost of treatment increased to $\$ A 12,474 .{ }^{[72]}$ When a DFU leads to lower extremity amputation, the median inpatient cost per admission was \$ A12,485 (confidence interval (CI): \$ A6,037-24,415), with a median length of stay of 24 (10-43) days. ${ }^{[66]}$ In 2007, the direct costs of managing diabetes and its complications in the US was US $\$ 116$ billion, with $33 \%$ of these costs directly related to the management of DFUs. ${ }^{[74]}$ A review in 2012 of the annual cost to treat DFUs in the UK was found to be over $£ 600$ million..$^{\text {75] }}$

The national guidelines on detection and prevention of diabetic foot problems in Type 2 diabetics, has not considered the direct influence of depression or any mental health disorder on foot ulcers. ${ }^{[72]}$ There is also no consideration of mental health influences, specifically depression and its relationship with DFUs, within the multidisciplinary evidenced-based clinical guideline for the assessment, investigation, and management of diabetes-related foot complications. ${ }^{[76]}$ Recent research has established the association between severity of PN symptoms and depressive symptoms. ${ }^{[57]}$ The results however were counterintuitive, as they did not demonstrate a significant association between DFUs and depressive symptoms. A possible conclusion outlined by this research is the fact that DFUs are painless, thus subjects have little emotional distress or discomfort from DFUs compared to 
PN pain, which can be unpredictable. ${ }^{[57]} \mathrm{A}$ more recent publication investigated the causal relationship between depression and DFUs, finding a significant interaction between depression and the occurrence of the first DFU; however, this relationship did not extend to recurrent foot ulcers. ${ }^{177]}$ This study demonstrated a strong relationship between the biological, psychological, and behavioral risks of foot ulcers, and the independent risk factor of depression, and suggested that the relationship between depression and a DFU is independent of any biological risk factors or foot self-care. ${ }^{[77]}$ The conclusion stated that interventions that target depression and foot selfcare behaviors prior to the occurrence of a DFU could maximize the successful prevention of an ulcer. ${ }^{[77]}$

There is strong evidence suggesting that stress can disrupt the body's ability to heal wounds. ${ }^{[78]}$ Wound healing is a biological process, achieved through specific phases: Hemostasis, inflammation, proliferation, and remodeling. For successful healing to occur, all four phases must occur sequentially and in a reasonable time frame. The disruption stress places on this process can be significant and can lead to healing delays; however, most research has focused on acute wounds and not chronic ones, such as DFUs. ${ }^{[79]}$

\section{Measuring Depression And Moving FORWARD}

Regardless of the well-documented prevalence of depression in diabetic patients, there remains little emphasis on the psychological aspects of diabetes in contemporary healthcare. ${ }^{[80]}$ The evidence linking a concurrent diagnosis of depression and diabetes to an increased mortality, a lower level of self-care, and an increased risk of poor or even nonhealing of DFUs, should prompt treating clinicians to be more aware of a patient's ability to cope on a day-to-day basis with both their diabetes and psychological malaise. ${ }^{[81]}$ Despite healthcare providers recognizing psychological symptoms in many patients, only $10 \%$ in Australia are referred for psychological assessment or care. ${ }^{[80]}$

National evidenced-based guidelines on type 2 diabetes mellitus conclude that a multidisciplinary specialist foot care team can reduce ulcerations and amputations in people with high-risk feet. ${ }^{[72]}$ The increased movement towards multidisciplinary foot clinics could include an increased awareness and management of patient's depression. Community health clinics, outpatient departments, and multidisciplinary foot clinics are well-positioned to initially identify people with, or at risk of, significant depressive symptoms, as well as monitor people over time. This may contribute to improved treatment adherence and quality of life, as well as reduced healthcare costs for persons with diabetes, since there is increasing evidence that primary care staff can be trained in basic psychological interventions for depression. ${ }^{[82]}$ There exists a number of easily administered depression scales for the healthcare provider to make better informed decisions on when and how to provide appropriate mental health referrals for patients. ${ }^{[83]}$ When depression is stabilized, patients have been shown to be able to engage more readily in self-management activities, which will help improve their depression, diabetes, and quality of life. ${ }^{[15]}$

\section{CONCLUSION}

It is clear from the existing literature that the healthcare costs of treating long-term neuropathic DFUs are significant. ${ }^{[6,72,75]}$ It is also well-established that there is a strong link between diabetes and depressed mood, with depression in this population contributing to increases in morbidity and mortality. ${ }^{[13-16,31,34]}$ The recent evidence of a substantial relationship between depression symptoms and DFU rates; with every standard deviation increase in depressive symptoms, associated with a $68 \%$ increase in risk of DFU, substantiates the need for further research in this area. ${ }^{[77]}$ Despite the observed prevalence of depressive symptoms by healthcare professionals in Australia ${ }^{[80]}$ and the recommendations of international guidelines that psychosocial symptoms need to be managed along with diabetes care, ${ }^{[60,61]}$ depression remains underrecognized and undertreated in the DFU patient population in Australia. The complex interaction between depression and diabetes has been established in diabetics with PN; ${ }^{[57,58]}$ however, the addition of DFU has further implications for the individual's capacity for self-care, ${ }^{[55]}$ and potentially increases the psychological impact of diabetes. With depression levels also known to be influenced by activity restriction, further research into the relationship between the limiting of activities of daily living for individuals with a DFU and levels of depressive symptoms is required.

This is where the integration of mental health specialists into the multidisciplinary treatment of patients with a DFU could assist in negotiating the specific balance between the medical and psychological model of treatment. Earlier intervention, diagnosis, and management of patients' depression may have implications for improved healing rates and reduced healthcare costs, not only in patients with PN as established, ${ }^{[57]}$ but also for those with DFUs as well. At this time there has been no published research investigating the relationship between depressive 
symptoms and healing rates of DFUs in Australia, and further research in this area is recommended.

\section{Acknowledgements}

The author would like to acknowledge the assistance of the Northern Hospital High Risk Foot Service, and the Northern Health Podiatry and Orthotics Departments for their assistance in data collection.

\section{Financial support and sponsorship}

Nil.

\section{Conflicts of interest}

There are no conflicts of interest.

\section{REFERENCES}

1. Diabetes in Australia. Available from: http://www. diabetesaustralia. com.au/Understanding-Diabetes/Diabetes-in-Australia/ [Last accessed on 2014 Aug 4].

2. Barnard KD, Peyrot M, Holt RI. Psychosocial support for people with diabetes: Past, present and future. Diabet Med 2012; 29:1358-60.

3. Singh N, Armstrong DG, Lipsky BA. Preventing foot ulcers in patients with diabetes. JAMA 2005;293:217-28.

4. Abbott CA, Vileikyte L, Williamson S, Carrington AL, Boulton AJ. Multicentre study of the incidence of and predictive risk factors for diabetic neuropathic foot ulceration. Diabetes Care 1998; 21:1071-5.

5. Wexler DJ, Grant RW, Wittenberg E, Bosch JL, Cagliero E, Delahanty L, et al. Correlates of health-related quality of life in type 2 diabetes. Diabetologia 2006;49:1489-97.

6. Hu J, Amoako EP, Gruber KJ, Rossen EK. The relationship among health functioning indicators and depression in older adults with diabetes. Issues Ment Health Nurs 2007;28:133-50.

7. Golden SH, Lazo M, Carnethon M, Berton AG, Schreiner PJ, Diez Roux AV, et al. Examining a bidirectional association between depressive symptoms and diabetes. JAMA 2008;299:2751-9.

8. Lustman PJ, Anderson RJ, Freedland KE, deGroot M, Carney RM, Clouse RE. Depression and poor glycemic control: A meta-analytic review of the literature. Diabetes Care 2000;23:934-42.

9. de Groot M, Anderson R, Freedland KE, Clouse RE, Lustman PJ. Associations of depression and diabetes complications: A meta-analysis. Psychosom Med 2001;63:619-30.

10. Whiteford H. National Health Priority Areas Report, Mental Health A Report Focusing on Depression. Ch. 2. Profile of Depression in Australia; 1998;37-56.

11. American Psychiatric Association, Diagnostic and statistical manual of mental disorders. $5^{\text {th }}$ ed. Arlington (CA): American Psychiatric Publishing; 2013.

12. Murray CJ, Lopez AD. Global mortality, disability, and the contribution of risk factors: Global Burden of Disease Study. Lancet 1997;349:1436-42.

13. Anderson RJ, Freedland KE, Couse RE, Lustman PJ. Prevalence of comorbid depression in adults with diabetes: A meta-analysis. Diabetes Care 2001;24:1069-78.

14. Ali S, Stone MA, Peters JL, Davies MJ, Khunti K. The prevalence of co-morbid depression in adults with Type 2 diabetes: A systematic review and meta-analysis. Diabet Med 2006;23:1165-73.

15. Lloyd CE, Hermanns N, Nouwen A, Pouwer F, Underwood L, Winkley K. The epidemiology of depression and diabetes: In:
Katon W, Maj M, Sartorius N, editors. Depression and Diabetes. Oxford: Wiley-Blackwell; 2010;1-27.

16. Pouwer F, Geelhoed-Duijveestihn HL, Tack CJ, Bazelmans E, Beekman AJ, Heine RJ, et al. Prevalence of co-morbid depression is high in outpatients with Type 1 or Type 2 diabetes mellitus. Results from the three outpatient clinics in the Netherlands. Diabet Med 2010;27:217-24.

17. Eaton WW, Armenian H, Gallo J, Pratt L, Ford DE. Depression and risk for onset of type II diabetes: A prospective population-based study. Diabetes Care 1996;19:1097-102.

18. Kawakami N, Takatsuka N, Shimizu H, Ishibashi H. Depressive symptoms and occurrence of type 2 diabetes among Japanese men. Diabetes Care 1999;22:1071-6.

19. Carnethon MR, Kinder LS, Fair JM, Stafford RS, Fortmann SP. Symptoms of depression as a risk factor for incident diabetes: Findings from the National Health and Nutrition Examination Epidemiologic Follow-up Study, 1971-1992. Am J Epidemiol 2003;158:416-23.

20. Arroyo C, Hu FB, Ryan LM, Kawachi I, Colditz GA, Speizer FE, et al. Depressive symptoms and risk of type 2 diabetes in women. Diabetes Care 2004;27:129-33.

21. Golden SH, Williams JE, Ford DE, Yeh HC, Paton Sanford C, Nieto FJ, et al., Atherosclerosis Risk in Communities study. Depressive symptoms and the risk of type 2 diabetes: The Atherosclerosis Risk in Communities Study. Diabetes Care 2004;27:429-35.

22. Carnethon MR, Biggs ML, Barzilay JI, Smith NL, Vaccarino V, Bertoni AG, et al. Longitudinal association between depressive symptoms and incident type 2 diabetes mellitus in older adults: The cardiovascular health study. Arch Intern Med 2007;167:802-7.

23. Everson-Rose SA, Meyer PM, Powell LH, Pandey D, Torréns JI, Kravitz HM, et al. Depressive symptoms, insulin resistance, and risk of diabetes in women at midlife. Diabetes Care 2004;27:2856-62.

24. Palinkas LA, Lee PP, Barrett-Connor E. A prospective study of Type 2 diabetes and depressive symptoms in the elderly: The Rancho Bernardo Study. Diabet Med 2004;21:1185-91.

25. Engum A. The role of depression and anxiety in onset of diabetes in a large population-based study. J Psychosom Res 2007;62:31-8.

26. Katon W, Lin, EH, Kroenke K. The association of depression and anxiety with medical symptom burden in patients with chronic medical illness. Gen Hosp Psychiatry 2007;29:147-55.

27. Paschalides C, Wearden AJ, Dunkerley R, Bundy C, Davies R, Dickens CM. The associations of anxiety, depression and personal illness representations with glycaemic control and health-related quality of life in patients with type 2 diabetes mellitus. J Psychosom Res 2004;57:557-64.

28. Peyrot M, Rubin RR. Levels and risks of depression and anxiety symptomatology among diabetic adults. Diabetes Care 1997;20:585-90.

29. Marcus MD, Wing RR, Guare J, Blair EH, Jawad A. Lifetime prevalence of major depression and its effect on treatment outcome in obese type II diabetic patients. Diabetes Care 1992;15:253-5.

30. Golden SH, Lee HB, Schreiner PJ, Diez Roux A, Fitzpatrick AL, Szklo M, et al. Depression and type 2 diabetes mellitus: The multiethnic study of atherosclerosis. Psychosom Med 2007;69:529-36.

31. DiMatteo MR, Lepper HS, Croghan TW. Depression is a risk factor for non-compliance with medical treatment: Meta-analysis of the effects of anxiety and depression on patient adherence. Arch Intern Med 2000;160:2101:7.

32. Ciechanowski PS, Katon WJ, Russo JE. Depression and diabetes: Impact of depressive symptoms on adherence, function, and costs. Arch Intern Med 2000;160:3278-85. 
33. Caruso LB, Silliman RA, Demissie S, Greenfield S, Wagner EH. What can we do to improve physical function in older persons with type 2 diabetes? J Gerontol A Biol Sci Med Sci 2000; 55:M372-7.

34. Katon W, Ciechanowski P. Impact of major depression on chronic medical illness. J Psychosom Res 2002;53:859-63.

35. Musselman DL, Betan E, Larsen H, Phillips LS. Relationship of depression to diabetes types 1 and 2: Epidemiology, biology, and treatment. Biol Psychiatry 2003;54:317-29.

36. Black SA. Increased health burden associated with comorbid depression in older diabetic Mexican Americans: Results from the Hispanic Established Population for the Epidemiologic Study of the Elderly survey. Diabetes Care 1999;22:56-64.

37. Padgett DK. Sociodemographic and disease-related correlates of depressive morbidity among diabetic patients in Zagreb, Croatia. J Ner Ment Dis 1993;181:123-9.

38. Lloyd CE, Matthews KA, Wing RR, Orchard TJ. Psychosocial factors and complications of IDDM. The Pittsburgh Epidemiology of Diabetes Complications Study. VIII. Diabetes Care 1992; 15:166-72.

39. Leedom L, Feldman M, Procci W, Zeidler A. Symptoms of sexual dysfunction and depression in diabetic women. J Diabet Complications 1991;5:38-41.

40. Robinson N, Fuller JH, Edmeades SP. Depression and diabetes. Diabet Med 1988;5:268-74.

41. Maraldi C, Volpato S, Penninx BW, Yaffe K, Simonsick EM, Strotmeyer ES, et al. Diabetes mellitus, glycemic control, and incident depressive symptoms among 70 to 79 year-old persons: The health, aging, and body composition study. Arch Intern Med 2007;167:1137-44.

42. Bastard JP, Maachi M, Lagathu C. Kim MJ, Caron M, Vidal H, Capeau J, Feve B. Recent advances in the relationship between obesity, inflammation, and insulin resistance Eur Cytokine Netw 2006;17:4-12.

43. Kiecolt-Glaser JK, Glaser R. Depression and immune function: Central pathways to morbidity and mortality. J Psychosom Res 2002;53:873-6.

44. Ford ES. Leukocyte count, erythrocyte sedimentation rate and diabetes incidents in a national sample of US adults. AM J Epidemiol 2002;155:57-64.

45. Schmidt MI, Duncan BB, Sharrett AR, Lindberg G, Savage PJ, Offenbacher $\mathrm{S}$, et al. Markers of inflammation and prediction of diabetes mellitus in adults (Atherosclerosis Risk in Communities study): A cohort study. Lancet 1999;353:1649-52.

46. Ford DE, Erlinger TP. Depression and C-reactive protein in US adults: Data from the Third National Health and Nutrition Examination Survey. Arch Intern Med 2004;164:1010-4.

47. Black $\mathrm{PH}$. The inflammatory response is an integral part of the stress response: Implications for atherosclerosis, insulin resistance, type II diabetes and metabolic syndrome X. Brain Behav Immun 2003;17:350-64.

48. Vickers, KS, Nies MA, Patten CA, Dierkhising R. Smith SA. Patients with diabetes and depression may need additional support for exercise. Am J Health Behav 2006;30:353-62.

49. Lin, EH, Katon W, Von Korff M, Rutter C, Simon GE, Oliver $\mathrm{M}$, et al. Relationship of depression and diabetes self-care, medication adherence, and preventive care. Diabetes Care 2004;27:2154-60.

50. Katon WJ, Von Korff M, Lin EH, Simon G, Ludman E, Russo J. The Pathways Study: A randonized trial of collaborative care in patients with diabetes and depression. Arch Gen Psychiatr 2004; 61:1042-9.

51. Jackson JL, DeZee K, Berbano E. Can treating depression improve disease outcomes? Ann Intern Med 2004;140:1054-6.
52. Gask L, Ludman E, Schaefer J. Qualitative study of an intervention for depression among patients with diabetes: How can we optimize patient-professional interactions? Chronic IIIn 2006;2:231-42.

53. Vileikyte L, Rubin RR, Leventhal H. Psychological aspects of diabetic neuropathic foot complications: An overview. Diabetes Metab Res Rev 2004;20:S13-8.

54. Veleikyte L, Leventhal H, Gonzalez JS, Peyrot M, Rubin RR, Ulbrecht JS, et al. Diabetic peripheral neuropathy and depressive symptoms: The association revisited. Diabetes Care 2005;28:2378-83.

55. Veleikyte L, Peyrot M, Gonzalez JS, Rubin RR, Garrow AP, Stickings $D$, et al. Predictors of depressive symptoms is persons with diabetic peripheral neuropathy: A longitudinal study. Diabetologia 2009;52:1265-73.

56. IDF Clinical Guidelines Task Force. Global Guideline for Type 2 Diabetes. Brussels: International Diabetes Federation; 2005.

57. NICE. Type 1 Diabetes: Diagnosis and Management of Type 1 Diabetes in Children, Young people and Adults. Clinical guideline 15. July 2004. Available from: http://www.nice.org.uk/guidance/ cg15 [Last accessed on 2015 Feb 10].

58. American Diabetes Association. Executive summary: Standards of medical care in diabetes. Diabetes Care 2010;33:S4-10.

59. National Evidence-Based Guidelines for the Management of Type 2 Diabetes 2011 Melbourne Australia. Available from: http://www.diabetesaustralia.com.au/For-Health-Professionals/ Diabetes-National-Guidelines/\#National-Evidence-BasedGuidelines-for-the-Management-of-Type-2-Diabetes [Last accessed on 2014 Oct 14].

60. National Evidence-Based Guidelines for the Prevention Identification and Management of Foot Complications in Diabetes (part of the guidelines on Type 2 Diabetes) 2011 Melbourne Australia. Available from: http://www. diabetesaustralia.com.au/For-Health-Professionals/DiabetesNational-Guidelines/\#National-Evidence-Based-Guidelines-forthe-Management-of-Type-2-Diabetes [Last accessed on 2014 Oct 14].

61. Collins RE, Lopez LM, Marteau TM. Emotional impact of screening: A systematic review and meta-analysis, BMC Public Health 2011;11:603.

62. Carver C, Scheier M, Michael F. Control Theory: A useful conceptual framework for personality-social, clinical and health psychology. Psychological Bulletin 1982;92:111-35.

63. Davis WA, Norman PE, Bruce DG, Davis TM. Predictors, consequences and costs of diabetes-related lower extremity amputation complicating type 2 diabetes: The Fremantle Diabetes Study. Diabetologia 2006;49:2634-41.

64. Australian Institute of Health and Welfare. Diabetes: Australian facts 2008. Canberra, 2008. (AlHW Cat. No. CVD 40; Diabetes Series No. 8). Available from: http://www.aihw.gov.au/publicationdetail/?id=6442468075 [Last accessed on 2011 Apr 01].

65. Edmonds M, Boulton A, Buckenham T, Every N, Foster A, Freeman D, et al. Report of the Diabetic Foot and Amputation Group. Diabet Med 1996;13:S27-42.

66. Reiber GE, Vileikyte L, Boyko EJ, del Aguila M, Smith DG, Lavery LA, et al. Causal pathways for incident lower-extremity ulcers in patients with diabetes from two settings. Diabetes Care 1999;22:157-62.

67. Currie CJ, Morgan CL, Peters JR. The epidemiology and cost of inpatient care for peripheral vascular disease, infection, neuropathy, and ulceration in diabetes. Diabetes Care 1998;21:42-8.

68. Calhoun JH, Overgaard KA, Stevens CM, Dowling JP, Mader JT. Diabetic foot ulcers and infections: Current concepts. Adv Skin Wound Care 2002;15:31-42. 
69. National Evidence-Based Guidelines for the Management of Type 2 Diabetes Mellitus Part 6 NHMRC 2005. p. 91. Available from: www.nhmrc.gov.au/_files_nhmrc/file/publications/synopses/di12. pdf [Last accessed on 2014 Mar 1].

70. Driver VR, Fabbi M, Lavery LA, Gibbons G. The costs of diabetic foot: The economic case for the limb salvage team. J Vasc Surg 2010;52:17S-22S.

71. Kerr M. Foot care in people with diabetes, the economic case for change, NHS Diabetes, Insight Health Economics March, 2012.

72. Wraight PR, Lawrence SM, Campbell DA, Colman PG. Creation of a multidisciplinary, evidence based, clinical guideline for the assessment, investigation and management of acute diabetes related foot complications. Diabet Med 2005;22:127-36.

73. Gonzalez JS, Vileikyte L, Ulbrecht JS, Rubin RR, Garrow AP, Delgado $\mathrm{C}$, et al. Depression predicts first but not recurrent diabetic foot ulcers Diabetologia 2010;53:2241-8.

74. Walburn J, Vedhara K, Hankins M, Rixon L, Weinman J. Psychological stress and wound healing in humans: $A$ systematic review and meta-analysis. J Psychosom Res 2009;67:253-71.

75. Veleikyte L. Stress and wound healing, Clin Dermatol 2007; 25:49-55.

76. Rutherford A, Wright E, Hussain Z, Colagiurii R, and on behalf of the Australian Dawn Advisory Committee. DAWN: Diabetes Attitude, Wishes and Needs, The Australian Experience. Sydney: Novo Nordisk Australasia; 2004.

77. Moor RG. Improving the treatment of depression in primary care: Problems and Prospects. Br J Gen Pract 1997;47:587-90.

78. Lloyd C. Depression: Screening tools, Diapedia, No. 9. Available from: http://www.diapedia.org/associated disorders/61047161602/depression-screening tools [Last accessed on 2013 Jun 10].

79. McKellar JD, Humphreys K, Piette JD. Depression increases diabetes symptoms by complicating patients' self-care adherence. Diabetes Educ 2004;30:485-92. 